\title{
Case Report: Clinical and Medicolegal Aspects of Fatal Imidacloprid Deliberate Self-poisoning: A Case Report
}

\author{
Vida Shiri-Ghaleh ${ }^{1,2}$, Salim Khani ${ }^{1}$,,${\text { Mehrdad } \text { Moradi }^{1} \text { Q }}_{\text {Kambiz Soltaninejad }}^{2^{*}}$ G \\ 1. Forensic Toxicology Laboratory, Legal Medicine Center, Kermanshah, Iran. \\ 2. Department of Forensic Toxicology, Legal Medicine Research Center, Legal Medicine Organization, Tehran, Iran.
}

\begin{tabular}{|l|l|}
\hline $\begin{array}{l}\text { Use your device to scan } \\
\text { and read the article online }\end{array}$ & $\begin{array}{l}\text { Citation: Shiri-Ghaleh V, KhaniS, Moradi M, Soltaninejad K. Clinical and Medicolegal Aspects of Fatal Imidacloprid De- } \\
\text { liberate Self-poisoning: A Case Report International Journal of Medical Toxicology and Forensic Medicine. 2021; 11(1):32228. } \\
\text { https://doi.org/10.32598/ijmtfm.v11i.32228 }\end{array}$ \\
def" https://doi.org/10.32598/ijmtfm.v11i.32228
\end{tabular}

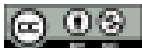

Article info:

Received: 12 Sep 2020

First Revision: 4 Oct 2020

Accepted: 13 Oct 2020

Published: 13 April 2021

\section{Keywords:}

Imidacloprid, Self-poisoning, Neonicotinoid insecticide

\begin{abstract}
A B S T RACT
Background: Imidacloprid is a neonicotinoid insecticide and agonist of nicotinic acetylcholine receptors. Despite its low toxicity profile, there are rare studies on its fatal poisoning. In this report, we described clinical and postmortem findings of a fatal imidacloprid poisoning.

Methods: A 33-year-old female presented to the emergency department with a history of deliberate consumption of unknown insecticide. On admission, she was drowsy and hypotensive with tachycardia and miotic pupils. Despite supportive therapy, she continued to be unconscious, with severe metabolic acidosis and developed a cardio-respiratory arrest and expired.
\end{abstract}

Results: A forensic autopsy was performed. The result of the toxicological analysis showed that imidacloprid concentrations were $267.8 \mu \mathrm{g} / \mathrm{mL}$ in femoral blood, $144.5 \mu \mathrm{g} / \mathrm{mL}$ in stomach content, and $292.3 \mu \mathrm{g} / \mathrm{mL}$ in bile.

Conclusion: Although imidacloprid is generally less toxic to humans high concentrations in biological samples could be considered lethal. Therefore, the educational programs about its toxicity should be considered for health care providers.

\section{Introduction}

I

midacloprid [1-(6-chloro-3-pyridylmethyl) -N-nitroimidazolidin-3-ylideneamine; CAS 138261-41-3] belongs to neonicotinoid insecticides, which are synthetic derivatives of nicotine. It is in the chloronicotinyl nitroguanidine chemical class [1]. Imidacloprid is the first and the commonest neonicotinoid insecticide used worldwide [2]. Other members of neonicotinoid insecticides are acetamiprid, thiacloprid, clothianidin, nitenpyram, and thiamethoxam [2]. Imidacloprid is an agonist of nicotinic Acetylcholine Receptors (nAChRs) and interferes with the transmission of neuronal impulses. It acts as a systemic insecticide through several types of postsynaptic nicotinic acetylcholine receptors in the nervous system [3]. Due to the different structures and compositions of nAChRs subunits between insects and mammals and a lower binding affinity for imidacloprid than that observed in insects, selective toxicity has been

${ }^{*}$ Corresponding Author:

Kambiz, Soltaninejad, PharmD, PhD.

Address: Department of Forensic Toxicology, Legal Medicine Research Center, Legal Medicine Organization, Tehran, Iran.

Tel: +98 (21) 55613731

E-mail: kamsoltaninejad@gmail.com 
observed [1, 3, 4]. Imidacloprid is classified as moderately hazardous (Class-II WHO) based on animal studies [1]. It is considered to be a relatively safe insecticide for mammals. Despite the low toxicity profile of imidacloprid in mammals, some studies are reporting accidental and intentional poisoning [5-16], and rare fatality cases have been reported [17-21].

In this report, we described clinical and postmortem findings of a fatal imidacloprid self-poisoning case with its quantitative analysis in postmortem biological samples.

\section{Case Presentation}

A 33-year-old housekeeper female from a rural area presented to the Emergency Department (ED) of a local hospital with a history of deliberate consumption of an unknown amount of an insecticide in a suicide attempt (15 $\mathrm{h}$ prior to admission) following the conflict with her spouse (according to her relatives' declaration). She had an acute episode of nausea, vomiting, abdominal cramps, and diarrhea for about 4-5 h. There was no significant comorbid medical illness and substance use disorder. On admission in ED, she was drowsy (Glasgow Coma Scale (GCS) score: 10/15), and was unable to stand unsupported. Her pulse was 88/min, and had Blood Pressure (BP) of $85 / 60 \mathrm{mmHg}$, respiratory rate of $16 / \mathrm{min}$, a body temperature of $37.5^{\circ} \mathrm{C}$, and had non-reacting miotic pupils.

Due to an initial lack of history, she was managed as a case of organophosphorus insecticide poisoning. Investigations demonstrated normal hemogram, serum creatinine of $0.9 \mathrm{mg} \%$, serum sodium of $138 \mathrm{mEq} / \mathrm{L}$, serum potassium of $2.9 \mathrm{mEq} / \mathrm{L}$, serum random blood sugar of $302 \mathrm{mg} \%$, serum urea of $33 \mathrm{mg} \%$, Prothrombin Time (PT) of 13 seconds, Partial Thromboplastin Time (PTT) of 37 seconds, and International Normalized Ratio (INR) was 1.1. Cardiac monitoring showed sinus tachycardia, Venous Blood Gas Analyzer (VBGA) showed $\mathrm{pH}$ of 7.36, $\mathrm{PO}_{2}: 64.8 \mathrm{mmHg}, \mathrm{PCO}_{2}: 20.5 \mathrm{mmHg}, \mathrm{O}_{2}$ saturation: $91.7 \%$, and $\mathrm{HCO}_{3}: 11.6 \mathrm{mmol} / \mathrm{L}$. She received gastric lavage, activated charcoal $(50 \mathrm{~g}) /$ sorbitol $(150 \mathrm{~mL}$ of $70 \%$ solution), crystalloid fluids, $2 \mathrm{mg}$ of atropine, and $1 \mathrm{~g}$ of pralidoxime in ED. Hypokalemia was corrected with $\mathrm{KCl}$ infusion. She continued to be unconscious with fixed dilated pupils and developed a cardio-respiratory arrest requiring endotracheal intubation and Cardiopulmonary Resuscitation (CPR) (17 h post-ingestion). At this time and after CPR, her pulse was $120 / \mathrm{min}$, BP was $110 / 70 \mathrm{mmHg}$, respiratory rate was $21 / \mathrm{min}$, and body temperature was $37.8^{\circ} \mathrm{C}$. She transferred to the Intensive Care Unit (ICU) of a referral hospital. Before transferring to ICU, she required epinephrine infusion to main- tain blood pressure. Worsening of cardiac function was as bradycardia and asystole and severe metabolic acidosis ( $\mathrm{pH}$ 6.95, $\mathrm{PCO}_{2}: 68.9 \mathrm{mmHg}, \mathrm{PO}_{2}: 103.8 \mathrm{mmHg}$, $\mathrm{HCO}_{3}: 15.3 \mathrm{mmol} / \mathrm{L}, \mathrm{O}_{2}$ saturation: $92.3 \%$ ) was noted. Despite supportive therapy, she died due to cardiac arrest on the way to the hospital ( $4 \mathrm{~h}$ after admission to ED). The decedent was transferred to the Forensic Medicine Center for medicolegal investigation and determination of the cause of death.

\section{Autopsy procedure}

A medicolegal autopsy was performed approximately $12 \mathrm{~h}$ after the death. The women's height was $165 \mathrm{~cm}$ and her weight was $70 \mathrm{~kg}$. There was no evidence of physical or congenital deformities or putrefaction. No traumatic lesions or defensive wounds were observed on the body. There was also no evidence of serious injury on the body except external CPR features in the chest and in-hospital injection marks on the left hand and right leg due to therapeutic procedures. Both eyes and her face were pale, and petechial hemorrhages were observed in the conjunctivae and sclera. There were no other soft tissue, cervical spine, laryngeal, or skeletal injuries and fractures on the neck. There was no congestion, submucosal injuries, hemorrhages, or erosion on the nasal cavity. However, there was mild erosion in the mucosal lining of the oral cavity and esophagus.

The heart, which weighed $410 \mathrm{~g}$, showed left ventricular hypertrophy with myocardial ischemic change and coronary artery stenosis. The left and right lungs showed congestion. Gastric content was fluid with no special odor. The kidneys had a normal appearance without urine. No other conditions were diagnosed macroscopically or microscopically. Biological samples, such as whole blood samples from the femoral vein, stomach contents, liver (right lobe) tissue, and bile were collected and submitted to the forensic toxicology laboratory for systematic toxicological analysis.

\section{Toxicological analysis}

All samples were screened using the validated HighPerformance Liquid Chromatography/Photodiode Array Detector (HPLC/PDA) and Gas ChromatographyMass Spectrometry (GC/MS) methods for systematic toxicological analysis in the forensic toxicology laboratory. In the qualitative screening method, imidacloprid was detected in the biological samples. Then, we used a previously validated HPLC-PDA for the confirmation and quantification of imidacloprid in biological samples [20]. In brief, after sample preparation using liquid-liq- 
uid extraction described previously, the samples were analyzed by an HPLC-PDA system. The HPLC system was a Knauer (Smartline, Berlin, Germany) with a quaternary pump and equipped with a Diode Array Detector (DAD, S2800). The separation was carried out on a Eurospher-100-5 C18 column (250 mm x $4.6 \mathrm{~mm}, 5$ $\mu \mathrm{m}$ particle size) with a Smart-1000 pump. A mixture of acetonitrile and phosphate buffer $(\mathrm{pH}=2.3)(63: 37 \mathrm{v} / \mathrm{v} \%)$ was used as elution solvent in isocratic mode. A $20-\mu \mathrm{L}$ sample was injected into the column and eluted at room temperature with a constant flow rate of $1 \mathrm{~mL} / \mathrm{min}$. The HPLC conditions were optimized to achieve the maximum response and the best peak shape and resolution.

The result of the analysis showed that imidacloprid concentration was $267.8 \mu \mathrm{g} / \mathrm{mL}$ in femoral blood, 144.5 $\mu \mathrm{g} / \mathrm{mL}$ in stomach content, $292.3 \mu \mathrm{g} / \mathrm{mL}$ in bile, and $19.1 \mu \mathrm{g} / \mathrm{g}$ in the liver tissue. There were no other toxic substances, including illicit drugs in the samples.

Due to medicolegal death investigations, including clinical history, forensic full autopsy examination, and postmortem toxicological findings, the cause of death was concluded as acute imidacloprid poisoning and the manner of death was suicide.

\section{Discussion}

Imidacloprid is a nAChRs agonist in the nervous system and induces neuronal dysfunctions. It is a highly selective nAChRs agonist with higher binding strength to insect nerve receptors in comparison with humans resulting in its safe toxicological profile $[1,4]$. In Iran, imidacloprid has been registered as different formulations of Suspension Concentrate (SC) 35\%, Water-dispersible powders (WS) $70 \%$, and Flowable Concentrates for Seed Treatment (FS) $6 \% \mathrm{w} / \mathrm{v}$ for agricultural uses and it is the most commonly used insecticide in Iran [22].

Although imidacloprid has been considered a safe insecticide for humans, its toxicity has been reported through oral or inhalation exposures [14-16]. Few case reports of fatal imidacloprid deliberate self-poisoning in attempted suicides have been described [17-21] and there are rare cases with postmortem toxicological analysis for detection of imidacloprid in postmortem samples $[6,9$, 20]. In a prospective case series study on accidental or inhalation exposure cases, the mild signs and symptoms, such as nausea, vomiting, headache, dizziness, abdominal pain, and diarrhea which were largely self-resolving without loss of consciousness and death were reported [9]. Dyspnea, liver injury, and neuropsychological impairment (irritability, twitching, delirium, disorientation, and lethargy) have been reported in mild to moderate intoxicated cases in previous reports [11, 13, 16, 21]. In severe and fatal cases, cardiovascular involvement (bradycardia, arrhythmia, ventricular fibrillation, hypotension, tachycardia, and cardiac arrest), rhabdomyolysis, and respiratory and liver failure have been reported $[8,17]$. In the present case, clinical presentations are in concordance with previous severe and fatal cases $[6,12,17,18]$.

There is not a specific antidote for the treatment of neonicotinoid insecticide poisoning and treatment is only based on supportive and symptomatic care [19]. Administration of antidote for organophosphorus pesticides poisoning (atropine and oximes) is contraindicated in neonicotinoid insecticide poisoning and can lead to severe fatal poisoning. In our case, treatment on admission to ED was performed by atropine and pralidoxime. It has been shown that the treatments of poisoned patients with imidacloprid using organophosphorus pesticides antidotes may increase the toxicity [9].

There are scant reports about imidacloprid concentrations in biological samples. For example, Mohamed et al. reported that the imidacloprid median concentration in mild to moderate intoxicated cases was $10.58 \mathrm{ng} / \mathrm{L}$ (range: $0.02-51.25 \mathrm{ng} / \mathrm{L}$ ) [9].

Fuke et al. detected a very high imidacloprid concentration in the femoral blood and cerebrospinal fluid in a fatal case (105 and $58.5 \mu \mathrm{g} / \mathrm{ml}$, respectively) [20]. They concluded that the high concentration of imidacloprid was related to very high ingestion of imidacloprid and ingestion of a mixture of an imidacloprid-based insecticide with an alcoholic beverage, leading to enhanced imidacloprid absorption. The imidacloprid insecticide in this case was a formulation containing $20 \% \mathrm{w} / \mathrm{v}$ of imidacloprid, which was ingested by the victim. Our results are in concordance with this report. In our case, we found higher concentrations of imidacloprid in femoral blood compared with other fatal cases reported in previous studies $[6,20]$. It may be due to the ingestion of concentrates formulations, which are provided in Iran's market (SC $35 \%$ and WS $70 \%$ of imidacloprid), sampling time, or high ingested amount of the imidacloprid by the patient. The lower concentration of imidacloprid in gastric content in comparison with femoral blood is due to the absorption of the poison according to the time elapsed from oral ingestion. Previous studies have demonstrated that imidacloprid can be rapidly absorbed in a very high rate of efficiency [23].

However, we considered the high imidacloprid concentrations in the body to be lethal. Because of negative 
postmortem toxicology results for common poisons and drugs, and no injury or disease, and the absence of evidence for an alternative cause of death (macroscopic or histological), we concluded that the cause of death in the case was imidacloprid acute poisoning.

\section{Conclusion}

This is a case of a deliberate self-poisoning in an attempted suicide by ingestion of a massive dose of imidacloprid. This case emphasizes the need for careful diagnosis and treatment. Imidacloprid is generally less toxic to humans causing mild symptoms and treatment should be performed based on supportive and symptomatic measures and it should not be regarded as an organophosphorus compound. However, the high imidacloprid concentrations in biological samples should be considered lethal. In this regard, suitable regulations and educational programs regarding its toxicity could be considered for health care providers and authorities.

\section{Ethical Considerations}

\section{Compliance with ethical guidelines}

The study was performed based on the ethical guidelines of the 1975 Declaration of Helsinki, revised in 1983. An informed consent was obtained from the legal relatives of the subject. Private information, including name and surname, was removed from the datasheet.

\section{Funding}

This research did not receive any grant from funding agencies in the public, commercial, or non-profit sectors.

\section{Author's contributions}

All authors contributed to preparing this article.

\section{Conflict of interest}

The authors declared no conflict of interest.

\section{Acknowledgements}

We would like to thank the staff of Kermanshah Legal Medicine Center for their kind cooperation.

\section{References}

[1] National Pesticide Information Center (NPIC). Imidacloprid technical fact sheet [Internet]. [Accessed 8 March 2020]. Available from: http://npic.orst.edu/factsheets/archive/imidacloprid.html

[2] Cimino AM, Boyles AL, Thayer KA, Perry MJ. Effects of neonicotinoid pesticide exposure on human health: A systematic review. Environ Health Perspect. 2017; 125(2):155-62. [DOI:10.1289/EHP515] [PMID] [PMCID]

[3] Zhang A, Kayser H, Maienfisch P, Casida JE. Insect nicotinic acetylcholine receptor: Conserved neonicotinoid specificity of [(3)H] imidacloprid binding site. J Neurochem. 2000;75(3):1294303. [DOI:10.1046/j.1471-4159.2000.751294.x] [PMID]

[4] Yamamoto I, Yabuta G, Tomizawa M, Saito T, Miyamoto T, Kagabu Sh. Molecular mechanism of select toxicity of nicotinoids and neonicotinoids. J Pestic Sci . 1995; 20(1):33-40. [DOI:10.1584/jpestics.20.33]

[5] Wu IW, Lin JL, Cheng ET. Acute poisoning with the neonicotinoid insecticide imidacloprid in N-methyl pyrrolidone. J Toxicol Clin Toxicol. 2001; 39(6):617-21. [DOI:10.1081/CLT100108494] [PMID]

[6] Proença P, Teixeira H, Castanheira F, Pinheiro J, Monsanto PV, Marques EP, et al. Two fatal intoxication cases with imidacloprid: LC/MS analysis. Forensic Sci Int. 2005; 153(1):7580. [DOI:10.1016/j.forsciint.2005.04.015] [PMID]

[7] Agarwal R, Srinivas R. Severe neuropsychiatric manifestations and rhabdomyolysis in a patient with imidacloprid poisoning. Am J Emerg Med, 2007; 25(7):844-5. [DOI:10.1016/j. ajem.2006.11.044] [PMID]

[8] David D, George IA, Peter JV. Toxicology of the newer neonicotinoid insecticides: Imidacloprid poisoning in a human. Clin Toxicol (Phila). 2007; 45(5):485-6. [DOI:10.1080/15563650701338229] [PMID]

[9] Mohamed F, Gawarammana I, Robertson TA, Roberts MS, Palangasinghe C, Zawahir S, et al. Acute human selfpoisoning with imidacloprid compound: A neonicotinoid insecticide. PLoS One. 2009; 4(4):e5127. [DOI:10.1371/journal. pone.0005127] [PMID] [PMCID]

[10] Panigrahi AK, Subrahmanyam DK, Mukku KK. Imidacloprid poisoning: A case report. Am J Emerg Med. 2009; 27(2):256.e5-6. [DOI:10.1016/j.ajem.2008.06.035] [PMID]

[11] Karatas AD. Severe central nervous system depression in a patient with acute imidacloprid poisoning. Am J Emerg Med. 2009; 27:1171.e5-7. [DOI:10.1016/j.ajem.2009.01.006] [PMID]

[12] Yeh IJ, Lin TJ, Hwang DY. Acute multiple organ failure with imidacloprid and alcohol ingestion. Am J Emerg Med. 2010; 28(2):255.e1-3. [DOI:10.1016/j.ajem.2009.05.006] [PMID]

[13] Viradiya K, Mishra A. Imidacloprid poisoning. J Assoc Physicians India. 2011; 59:594-5. [PMID]

[14] Agha A, Bella A, Aldosary B, Kazzi ZN, AlHumaidi MA. Imidacloprid poisoning presenting as leukoclastic vasculitis with renal and hepatic dysfunction. Saudi J Kidney Dis Transpl. 2012; 23(6):1300-3. [DOI:10.1016/j.ajem.2009.05.006] [PMID]

[15] Kumar A, Verma A, Kumar A. Accidental human poisoning with a neonicotinoid insecticide, imidacloprid: A rare case re- 
port from rural India with a brief review of literature. Egyptian J Forensic Sci. 2013; 3(4):123-6. [DOI:10.1016/j.ejfs.2013.05.002]

[16] Sriapha C, Trakulsrichai S, Intaraprasong P, Wongvisawakorn S, Tongpoo A, Schimmel J, et al. Imidacloprid poisoning case series: Potential for liver injury. Clin Toxicol (Phila). 2020; 58(2)136-8. [DOI:10.1080/15563650.2019.1616091] [PMID]

[17] Huang NC, Lin SL, Chou CH, Hung YM, Chung HM, Huang ST. Fatal ventricular fibrillation in a patient with acute imidacloprid poisoning. Am J Emerg Med. 2006; 24(7):883-5. [DOI:10.1016/j.ajem.2006.03.008] [PMID]

[18] Shadnia Sh, Moghaddam HH. Fatal intoxication with imidacloprid insecticide. Am J Emerg Med. 2008; 26(5):634.e1-4. [DOI:10.1016/j.ajem.2007.09.024] [PMID]

[19] Iyyadurai R, George IA, Peter JV. Imidacloprid poisoningnewer insecticide and fatal toxicity. J Med Toxicol. 2010; 6(1):77-8. [DOI:10.1007/s13181-010-0041-6] [PMID] [PMCID]

[20] Fuke C, Nagai T, Ninomiya K, Fukasawa M, Ihama Y, Miyazaki T. Detection of imidacloprid in biological fluids in a case of fatal insecticide intoxication. Leg Med (Tokyo). 2014; 16(1):40-3. [DOI:10.1016/j.legalmed.2013.10.007] [PMID]

[21] Mundhe SA, Birajdar SV, Chavan SS, Pawar NR. Imidacloprid poisoning: An emerging cause of potentially fatal poisoning. Indian J Crit Care Med. 2017; 21(11):786-8. [DOI:10.4103/ ijccm.IJCCM_152_17] [PMID] [PMCID]

[22] Iran Plant Protection Organization. List of registered pesticides [Internet]. 2019. [Accessed 11 July 2019]. Avialble from: https://ppo.ir/_douranportal/documents/control-afat/allowed\%20insecticide.pdf

[23] Tomizawa M, Casida JE. Neonicotinoid insecticide toxicology: Mechanisms of selective action. Annu Rev Pharmacol Toxicol. 2005; 45:247-68. [DOI:10.1146/annurev.pharmtox.45.120403.095930] [PMID] 